Document downloaded from:

http://hdl.handle.net/10251/158934

This paper must be cited as:

Baselga Moreno, S. (2019). TestGrids: Evaluating and Optimizing Map Projections. Journal of Surveying Engineering. 145(3):1-8. https://doi.org/10.1061/(ASCE)SU.19435428.0000279

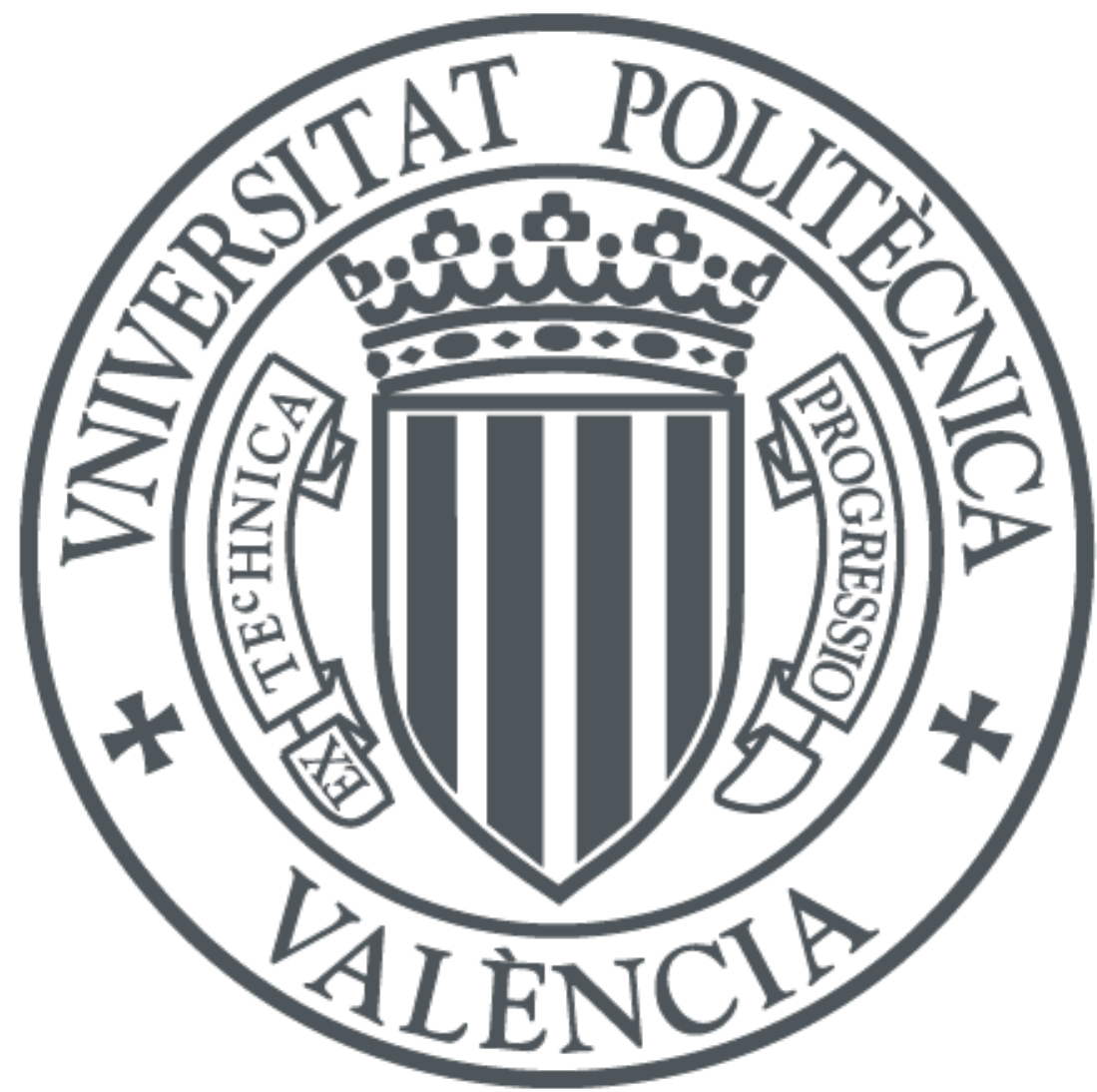

The final publication is available at

https://doi.org/10.1061/(ASCE)SU.1943-5428.0000279

Copyright American Society of Civil Engineers

Additional Information 


\title{
SU933
}

\section{TestGrids: Evaluating and Optimizing Map Projections}

\author{
Sergio Baselga, M.ASCE
}

${ }^{1}$ Cartographic Engineering, Geodesy and Photogrammetry Dept., Universitat Politècnica de València, 46022 València, Spain, e-mail: serbamo@cgf.upv.es

\begin{abstract}
In the study of map projections it is relatively simple to obtain meaningful estimators of distortion for a small area. The definition and especially evaluation of global distortion measures (i.e. estimators representing the distortion worldwide or in a continent-like area) are undoubtedly more troublesome. Therefore it is relatively common to find that recommendations for the parameters to use in a particular map projection, be it devised for a continent or a country, are only based on simple rules (like the one-sixth rule of thumb for conic projections) with no possibility of further improvement in terms of resulting distortions and sometimes even with no knowledge at all of the size of these distortions. While the choice of map defining parameters is normally made for reasons other than distortion minimization, such as ease of use (e.g. integer or half-integer numbers may be preferable), preservation of conventional or traditional definitions, uniformity of parameters between neighboring regions, etc., it is always worthwhile to know the optimal set of parameters in terms of minimal distortion. Then the cartographer may mindfully deviate from it, documenting the difference in defining parameters as well as in resulting distortions. The present research provides a
\end{abstract}


means to do so by extending a related work presented in a previous contribution where the evaluation and optimization of distortions were studied for a single map projection and two areas of interest only. To this end, a new tool has been developed and it is now presented. It is open to the use by the journal readers and permits to evaluate several measures of distortion for the most common conformal and equal-area projections within the geographic boundaries of interest defined by the user. Also embedded in the tool and transparent to the user, global optimization techniques operating on Fibonacci grids permit the optimization of parameters for the particular map projection and area of interest under two possible criteria: minimization of typical distortion or minimization of extreme distortions. These tool and techniques are applied to several official projections in order to analyze their original performances and propose new parameters that significantly improve the resulting distortions, while leaving room for the reader to easily evaluate and optimize for the lowest distortions these projections within their regions of interest.

Author keywords: Map projections; distortion; global optimization; Fibonacci grids.

\section{Introduction}

Leonardo Pisano, alias Fibonacci, presented in the early 13th century his famous sequence $1,1,2,3,5,8,13 \ldots$, which over the centuries has been shown to appear in many disparate fields in nature, from sunflowers to hurricanes or galaxies (see e.g. Koshy 2001). The ratio of two consecutive numbers in the Fibonacci sequence 
approaches monotonically the number known as golden ratio, which serves to construct a Fibonacci spiral and, with several turns of the spiral, a Fibonacci grid, which may be used to homogeneously cover a geographic area of interest (see e.g. González 2010 or Keinert et al. 2015). The resulting sampling is much more efficient than the standard latitude-longitude sampling, so that an extremely smaller sample (i.e. being the number of test points several orders of magnitude less) may yield results of better accuracy, thus enabling quick evaluations of interest for numerical modeling (Swinbank and Purser 2006). This explains the remarkable growth in its usage in geosciences that has been seen in recent years. In the field of map projections, the author has recently presented an application of Fibonacci grids combined with global optimization techniques for the evaluation and optimization of the Lambert Conformal Conic projection distortions (Baselga 2018). The complexity of the equation that needs to be numerically integrated over an asymmetric region (due to meridian convergence) explains the use of Fibonacci grids, while heuristic optimization techniques are required due to the complexity inherent to obtaining the optimum of several parameters that belong to the equation that is being integrated.

A map projection is a functional relationship bringing a point on the earth's reference surface (be it a ellipsoid or a sphere) to a point on the plane, and vice versa. Due to the intrinsic differences between these two surfaces (one with curvature, the other without), the appearance of some distortions are inevitable. While the local study of local measures of distortion is straightforward by computing, for instance, the scale distortion factor (ratio between a differential length on the plane and the corresponding length on 
the original reference surface) or the Tissot's indicatrix ellipse (Snyder 1987), global distortion measures that meaningfully characterize the behavior of map projection within some prescribed boundaries are not so obvious and broadly accepted. Some of the approaches to characterize this general distortion were proposed more than a century ago, such as the integral evaluations of Airy's and Jordan's measures (see Airy 1861 and Jordan 1896, respectively), or several decades ago, Gilbert's and Peters's estimators (see Gilbert 1974 and Peters 1975, respectively; or Canters 2002 for a general presentation). The estimator called typical distortion was used in Baselga (2018) for the purpose of evaluation and optimization of the Lambert Conformal Conic projection in two areas of interest (Europe and Spain). It is defined as the mean squared deviation from unity (which is the optimal value) of the scale distortion factor in the mapping domain. Due to its resemblance to a well-known estimator broadly used in statistics - the standard deviation - it is easy to understand and has an easy interpretation: it represents the typical dispersion in the sample from the optimal value (one). Nevertheless, a detailed analysis of the distortions introduced by a map projection should not be based on the study of a single estimator only, but rather on the careful inspection of different distortion measures.

This research presents and uses a tool, which is available to the journal readers in the form of a standalone application, for the analysis not only of the Lambert Conformal Conic projection but also of the other most commonly used conformal projection, the Transverse Mercator projection, as well as the most commonly used equal-area 
projections, namely the Albers Conic Equal-Area projection and the Lambert Azimuthal Equal-Area projection.

Among the existing conformal projections, the Lambert Conformal Conic projection is especially well-suited for mid latitudes and regions with east-to-west predominant extension (Snyder 1987, Kopp and Kennedy 2000, Meyer 2010). It can be designed to have one or, as it is more common, two standard parallels. It is normally used for small scales, that is smaller or equal to $1: 500,000$, like the case of the 1:500,000-scale State base maps for the 48 contiguous United States (Snyder 1987), or in the commandment by the European Commission directive for spatial information INSPIRE D2.8.I.1 (2014) to use this projection "for conformal pan-European mapping at scales smaller than or equal to 1:500,000". The Lambert Conformal Conic projection is also used for States with large east-west extent as defined in the State Plane Coordinate Systems of 1983 (Stem 1989).

By contrast, the Transverse Mercator projection is the best choice for conformal mapping of areas having a south-to-north predominant extension (Meyer 2010). Scale distortion is only slightly affected by factors other than the distance from the central meridian, which can be held true to scale or mapped at a reduced scale so that the mean scale of the entire area of interest is improved (Snyder 1987). Being normally used for large scales (usually larger than 1:500,000), it is, for example, the official projection for many States as defined in the State Plane Coordinate Systems of 1983 
(Stem 1989) and the European INSPIRE directive commands its use for "conformal pan-European mapping at scales larger than 1:500,000" INSPIRE D2.8.I.1 (2014).

Referring now to the equal-area projections, it is worth remembering that they generally preserve neither angles nor scales, but the distortions introduced are compensated in a way that areas are effectively preserved. The two equal-area projections most widely used are the Albers Conic Equal-Area projection (Albers projection, for short) and the Lambert Azimuthal Equal-Area projection. To date, the preference seems to have been a matter of taste or custom, for instance, Albers projection in the U.S. (e.g. the National Atlas, Snyder 1987) and Lambert Azimuthal Equal-Area in Europe ("for pan-European spatial analysis and reporting, where true area representation is required", INSPIRE 2014). The tool presented will be used to evaluate and compare the respective distortions introduced for some areas of interest, and optimize their defining parameters so that distortion is minimized.

Choosing a set of defining parameters for a particular map projection and particular area-of-use that minimizes one of the above-mentioned general measures can produce unacceptably high distortion values for some particular places, so the tool offers the additional possibility of favoring the control of extreme distortions rather than the general distortion by means of the implementation of the estimator presented in the following section. The tool and techniques will be finally applied to several regions and official projections in order to analyze their original performances and the corresponding improvements after optimization of their defining parameters. 


\section{Materials and methods}

\section{Distortion measures}

Given a pair of infinitesimally close points a scale distortion factor $k_{1}$ can be defined as the ratio between the projected distance on the grid $d s^{\prime}$ and the original distance $d s$ on the ellipsoid of reference, and can be computed with the general expression

$$
k_{1}=\frac{d s^{\prime}}{d s}=\frac{\sqrt{\left(x_{\varphi}^{2}+y_{\varphi}^{2}\right) d \varphi^{2}+\left(x_{\lambda}^{2}+y_{\lambda}^{2}\right) d \lambda^{2}+2\left(x_{\varphi} x_{\lambda}+y_{\varphi} y_{\lambda}\right) d \varphi d \lambda}}{\sqrt{\rho^{2} d \varphi^{2}+v^{2} \cos ^{2} \varphi d \lambda^{2}}}
$$

where $x_{\varphi}, x_{\lambda}, \mathrm{y}_{\varphi}, y_{\lambda}$ are the partial derivatives of the map projection defining functions $x$ and $y$ with respect to the geodesic coordinates latitude $\varphi$ and longitude $\lambda, \rho$ and $v$ are the principal radii of curvature of the ellipsoid in the meridian and the prime vertical, respectively, and $d \varphi$ and $d \lambda$ are the differential coordinate increments from the first point to the second point (Baselga 2014, 2018). This scale distortion factor has a point-like or local meaning (i.e. it is valid only for infinitesimal lengths, say only a few meters on the earth surface).

Scale distortions along the meridian and along the parallel are customary denoted by $h$ and $k$, respectively (Snyder 1987), so that substituting in Eq. (1) zero for $d \lambda$, in the case of $h$, and zero for $d \varphi$, in the case of $k$, one obtains respectively 


$$
h=\frac{\sqrt{x_{\varphi}^{2}+y_{\varphi}^{2}}}{\rho}
$$

$$
k=\frac{\sqrt{x_{\lambda}^{2}+y_{\lambda}^{2}}}{v \cos \varphi}
$$

In conformal projections $h$ and $k$ are equal, since the scale distortion factor, $k_{1}$ in Eq. (1), is only point-dependent and not direction-dependent (Snyder 1987, Onursal and Kizilsu 1999). The expressions for this scale distortion factor in the Lambert Conformal Conic and the Transverse Mercator projections with the ellipsoid as reference surface are readily found in the literature (e.g. Snyder 1987, Annoni et al. 2003).

For equal-area projections $h$ and $k$ are not equal but inverse to each other, $h=1 / k$ (Snyder 1987). Whilst for the case of the Albers Conic Equal-Area projection with the ellipsoid as reference surface expressions for $h$ and $k$ can be found e.g. in Snyder (1987), they are not easily found in the literature for the case of Lambert Azimuthal Equal-Area projection with ellipsoidal surface. The expressions to compute $k$ from Eq. (3) for this projection ( $h$ being simply obtained as $h=1 / k$ ) are therefore given now. 
Starting from the map projection defining functions $x$ and $y$ given in Annoni et al. (2003, p.125), which coincide with those in Snyder (1987, p.187) except for a slight change in notation, one may obtain the following partial derivatives with respect to longitude $\lambda$ :

$$
\begin{gathered}
x_{\lambda}=B_{\lambda} D \cos \beta \sin \left(\lambda-\lambda_{0}\right)+B D \cos \beta \cos \left(\lambda-\lambda_{0}\right) \\
y_{\lambda}=\frac{B_{\lambda}}{D}\left[\cos \beta_{0} \sin \beta-\sin \beta_{0} \cos \beta \cos \left(\lambda-\lambda_{0}\right)\right]+\frac{B}{D} \sin \beta_{0} \cos \beta \sin \left(\lambda-\lambda_{0}\right)
\end{gathered}
$$

with

$$
B_{\lambda}=\frac{R_{q}}{\sqrt{2}} \cos \beta_{0} \cos \beta \sin \left(\lambda-\lambda_{0}\right)\left[1+\sin \beta_{0} \sin \beta+\cos \beta_{0} \cos \beta \cos \left(\lambda-\lambda_{0}\right)\right]^{-\frac{3}{2}}
$$

using all the auxiliary variables $R_{q}$, $\beta$, etc. as defined in Annoni et al. (2003 p.124-125) or Snyder (1987, p.187). As a note of caution here, it has to be noted that the square root of 2 in the numerator of $B$ given in Snyder $(1987$, p.187) is correct whereas the 2 in the numerator of $B$ given in Annoni et al. (2003 p.125) is not. Eqs. (4)-(5) into Eq. (3) permit to obtain the scale distortions along the parallel $(k)$ and then along the meridian $(h=1 / k)$.

To characterize the overall scale distortion within a desired area of interest it was proposed in Baselga (2018) for the case of conformal projections the use of the typical distortion $\Delta k_{1}$ computed for a sufficiently large representative sample of $n$ points as 


$$
\Delta k_{1}=\sqrt{\frac{1}{n} \sum_{i=1}^{n}\left(k_{1_{i}}-1\right)^{2}}
$$

In the case of equal-area map projections, for which the scale distortion coefficient $k_{1}$ takes on different values along the meridian and the parallel, the estimator definition can be modified as

$$
\Delta k_{1}=\sqrt{\frac{1}{2 n} \sum_{i=1}^{n}\left[\left(h_{i}-1\right)^{2}+\left(k_{i}-1\right)^{2}\right]}
$$

This expression equals the definition given in Eq. (7) if used for a conformal projection (since $h$ equals $k$ for every point).

Similar to the estimator based on squared differences with respect to one, one could study the arithmetic average of the scale distortion coefficient $k_{1}$ (or of $h$ and $k$ ), $\overline{k_{1}}$. This measure yields, however, only information about the central value of the scale distortion factor (the closer to one the better) but no information about its dispersion. Other distortion measures, e.g. Gilbert's and Peter's estimators, $E_{G}$ and $E_{P}$, respectively, may also be useful to inform about the size of typical errors (see Gilbert 1974, Peters 1975, Canters 2002 or Baselga 2018 for their definition and use) and will be used in the tool and subsequent examples. Analogously to the modification from Eq. (7) to Eq. (8) it is 
suggested that in the case of equal-area projections, $h$ and $k$ are accounted for in the computation of the corresponding measures $\overline{k_{1}}, E_{G}$ and $E_{P}$.

Finally, it can also be useful to know the most extreme distortions within the area of interest, $k_{1 \max }$ and $k_{1 \min }$ and require them to be minimum with respect to one. For this purpose, a suitable objective function to be minimized over the representative sample of $n$ points by means of a global optimization method can be defined as

$$
\text { extreme_k } \mathrm{k}_{1}=\max _{\mathrm{n}}\left\{\operatorname{abs}\left(\mathrm{k}_{1 \max }-1\right), \operatorname{abs}\left(1-\mathrm{k}_{1 \min }\right)\right\}
$$

\section{Global optimization of defining parameters}

When a map projection is to be used for a particular area of interest, some of its defining parameters can be optimized so that the resulting distortions are optimal in a sense. It is well-known, for instance, the one-sixth rule of thumb for conic projections consisting in the definition of standard parallels at $1 / 6$ th of the maximum and minimum latitudes of interest (e.g. Kopp and Kennedy 2000, Fenna, 2007).

Minimization of the typical distortion estimator - Eq. (8) - or, alternatively, minimization of extreme distortions - Eq. (9) - both for the area of interest by means of a suitable global optimization method is proposed now.

Among the most successful global optimization methods, one can find the Simulated Annealing method, which emulates the process of self-construction of crystalline 
networks observed in nature. Without delving now into its technicalities it can simply be said that it consists in an ordered heuristic trial-and-error search conducted within the desired parameter domain that, if driven properly, converges to the global optimum of the function being minimized. The reader is referred to the presentation of the method given in the general literature (e.g. Pardalos and Romeijn 2002) or some particular applications to surveying problems presented by the author (e.g. Baselga 2007, 2011, where a Matlab code for implementing the Simulated Annealing method for the case at hand is given in the latter).

Other global optimization methods, such as Genetic Algorithms (e.g. Baselga 2007), Particle Swarm Optimization (e.g. Singh et al. 2016), the Shuffled Frog-leaping Algorithm (e.g. Yetkin and Berber 2013) or even some stochastic gradient descent method (e.g. Konečný et al. 2017) due to the smooth nature of the objective function, could have been equally used to successfully solve for the optimal parameters of the particular projection within the prescribed boundaries. As always when confronted with an heuristic method to obtain the global optimum for a problem, the user should check the necessary, though not sufficient, condition that successive executions of the algorithm yield the same result (possibly with negligible discrepancies). This can easily be checked with the tool described in the following section.

\section{TestGrids tool}

TestGrids has been developed by the author in Matlab using its guide tool for the design of the Graphical User Interface (GUI), which enables the redistribution to end users who 
do not have MATLAB installed. It can be downloaded from the author's personal web page http://personales.upv.es/serbamo/TestGrids/index.htm (password "JSurvEng2018").

Its layout favors comparisons at a glance since all distortion measures for the different map projections, evaluated both for the official defining parameters as well as for the optimized ones, can be displayed simultaneously, as can be seen in Fig. 1 .

The user can define the area of interest (maximum and minimum latitude and longitude), some special properties including the parameters of the global optimization method (the default values may be adequate for the majority of situations) and the total number of points - referred to the entire Earth - to construct the Fibonacci lattice (the default value is here appropriate for large, continent-like areas, smaller areas possibly requiring a larger number of points). The user can also define the map projection defining parameters: latitude of standard parallels, latitude and longitude of origin or central meridian, and central meridian scale factor, where applicable. By clicking on "Evaluate" the application computes the distortion measures for the corresponding projection and area of interest. By clicking on "Optimize" the best map projection defining parameters are computed in terms of minimum typical distortion or minimum extreme distortions (this can also be selected by the user), as well as the resulting distortion measures for the projection and area of interest.

\section{Examples of application}

\section{Lambert Conformal Conic projection}




\section{Europe}

Baselga (2018) computed the typical distortion for the Lambert Conformal Conic projection with the standard parallels and geographic boundaries for Europe defined in Annoni et al. (2003), later adopted by the INSPIRE directive as the official projection "for conformal pan-European mapping at scales smaller than or equal to $1: 500,000 "$ (INSPIRE D2.8.I.1 2014). This projection and corresponding area of use are referred to as EPSG3034 in the International Association of Oil \& Gas Producers (OGP) database, which has become a standard for the definition of coordinate reference systems (International Organization for Standardization, 2007).

The values for the standard parallels were optimized so that the typical distortion for the area of interest was reduced $10 \%$ with respect to the use of official standard parallels. This was at the cost, however, of increasing the extreme distortions appearing in the area. Now the question is revisited so that this projection is also optimized in the sense of minimum extreme values within the area of interest, Eq. (9).

Table 1 shows the distortion measures for three definitions of the standard parallels: the official according to INSPIRE D2.8.I.1 (2014), the best choice for minimum typical distortion and the best for minimum extreme distortions, computed all of them by means of TestGrids using its default values for the total number of points in the Fibonacci lattice and parameters in the Simulated Annealing method. Minimum numerical discrepancies of negligible significance could be found by changing some of these parameters (for instance, increasing the number of points in the Fibonacci lattice to 
obtain a much more accurate result at the cost of increasing the computing time). Unless explicitly stated it is assumed that all results shown in the paper have been obtained by TestGrids with its default parameters.

The best choice of standard parallel latitudes for the case of Europe seems not evident as one could make a case for each of the three options: the solution with minimum typical distortion in the area of interest is suboptimal in the sense that it has a maximum distortion value that is higher than the other two, being this value (67567 ppm) possibly too large for being acceptable; by contrast, the solution with minimum extreme distortions may be considered inacceptable in terms of both the typical and average distortion estimators; finally, the standard parallels according to INSPIRE D2.8.I.1 (2014) may not be optimal in minimizing a certain distortion measure but they may represent a certain compromise between the other two solutions.

Contrary to this case, the following examples show some applications where the best choice is unmistakably clear. In some cases this will lead us to propose a change in the currently used map defining parameters.

\section{Australia}

Now the attention is turned to the Geoscience Australia Standard National Scale Lambert Projection, EPSG17362, which is used to depict onshore territories in a single representation. The resulting distortion measures for the prescribed standard parallels and area of use are shown in Table 2 along with the computed optimum values and 
resulting measures for the optimal solutions in terms of minimum typical distortion and minimum extreme distortions.

As it can be seen the standard parallels used in EPSG17362 are already relatively well optimized for the entire area of use in the sense of low typical distortion. However, it is also true that a change in the defining standard parallels to those shown in the penultimate row of the table will not only produce considerably smaller maximum distortions (some 22000 ppm instead of some 32000 ppm, i.e. a $69 \%$ reduction) but also a typical distortion that is only a bit higher that the best possible one (some 1500 ppm instead of some 1300 ppm, i.e. a 15\% increase). One could propose, though this would not be indisputable, a change in the definition of standard parallel latitudes, so that, rounding to the next integer, pupper $=15^{\circ} S$ and plower $=39^{\circ} S$ be used, leading to the distortion measures shown in the last row of Table 2, which can be regarded easier to use and equivalent in practice to those displayed in the previous row.

\section{Conterminous US}

Now the distortion measures for the USA Contiguous Lambert Conformal Conic projection, ESRI projection 102004 (ESRI 2013), within the boundaries known as CONUS onshore (EPSG1323) are evaluated and the optimal solutions for minimum typical distortion and minimum extreme distortions are studied. This projection is used for instance in the National Hydropower Map (United States Department of Energy, 2013). The results of the analysis are shown in Table 3. As it can be seen the prescribed standard parallels are optimized neither in the sense of minimum typical 
distortion (which results in $9132 \mathrm{ppm}$ whereas the optimal solution is $7099 \mathrm{ppm}$ ) nor for minimum extreme distortions (they reach 25828 ppm compared with only 11950 ppm in the optimal solution, which represents a $54 \%$ reduction in the maximum distortion). One could propose, for instance, that the standard parallel latitudes be changed to those minimizing the typical distortion pupper $=44.07^{\circ} \mathrm{N}$ and (lower $=29.63^{\circ} \mathrm{N}$, since its use provides lower typical, average and extreme distortions, as well as lower Gilbert's and Peter's estimators than the current values in use.

\section{US State Plane Coordinate Systems}

Each US state has a State Plane Coordinate System (SPCS) for use in surveying and mapping (Stem 1989). Although the majority of states use the Transverse Mercator projection, some of them, having a large east-to-west extent, use the Lambert Conformal Conic projection. After analyzing several of these it has been found that the majority of SPCSs are already well optimized either in the sense of minimum extreme distortions (e.g. Texas Central) or in the sense of minimum typical distortion (e.g. Texas North). However, it may be worth showing now but one example where the currently used standard parallel latitudes could be modified for significant distortion reduction. It is the case of Nebraska, EPSG2819, whose distortion figures are displayed in Table 4. It is worth noting that the area of interest is now of much small extent (non continent-like), therefore a larger number of points for the entire Fibonacci lattice was used $(5,000,000$ instead of the ten times smaller default value) in order to obtain more accurate results.

From these results one could propose the adoption of the standard parallels pupper $=$ $42.37^{\circ} \mathrm{N}$ and plower $=40.63^{\circ} \mathrm{N}$, which produces some $50 \%$ reduction for both the typical 
distortion (from $249 \mathrm{ppm}$ to $118 \mathrm{ppm}$ ) and extreme distortions (from $-341 \mathrm{ppm}$ to -173 $\mathrm{ppm})$ in the area of interest.

\section{Transverse Mercator projection}

\section{US State Plane Coordinate Systems}

Similarly to the previous example, SPCSs that use the Transverse Mercator projection can also be studied. The cases of Florida East and Florida West (EPSG2777 and EPSG2778, respectively) are dealt with as illustrative examples. In the case of the Transverse Mercator projection, the variables to optimize for the area of interest are only the scale factor of the central meridian as well as the central meridian longitude (ideally centered in the area). As in the previous example, a large number of points for constructing the entire Fibonacci lattice (10 million instead of the smaller default value) is used aiming at higher accuracy. In Tables 5 and 6 it can be seen that the SPCSs could be optimized especially in terms of their extreme distortions (reaching 165 and $161 \mathrm{ppm}$ in Florida East and Florida West, respectively). Apart from the use of the optimal central longitude for each SPCS, a unique central meridian scale factor for both SPCSs (e.g. $k_{0}=0.999918$ ) could also be used by which the resulting distortions are always below $100 \mathrm{ppm}$ and the typical distortion is equal or better than those for the current definitions (see last row in both tables).

\section{UTM}

Universal Transverse Mercator (UTM) is a particular case of the Transverse Mercator projection where the globe is divided into 60 zones, each spanning six degrees of 
longitude and having their own central meridian, to which a scale factor $k_{0}=0.9996$ is applied. Some easting and northing offsets (the latter only to points in the Southern hemisphere), which have no influence on the resulting distortions, are applied to coordinates. The projection has a range of use between $80^{\circ} \mathrm{S}$ and $84^{\circ} \mathrm{N}$, thus avoiding regions much closer to the poles where distortions would be clearly inacceptable. It is the standard projection in many countries and it is used for many applications in geosciences (e.g. Soler and Wang 2016, El-Mowafy and Bilbas 2016, Mozas-Calvache and Pérez-García 2017, Agüera-Vega et al. 2017).

If the distortion measures are computed for any of these UTM zones (say zone 31 from $0^{\circ} \mathrm{E}$ to $6^{\circ} \mathrm{E}$ ) between their limits of use $80^{\circ} \mathrm{S}$ to $84^{\circ} \mathrm{N}$ one obtains the values shown in Table 7 along with the optimized scale factor (in the sense of both minimum typical distortion and minimum extreme values) and their corresponding distortion measures. It can be seen that the defining scale factor of the central meridian is mostly optimized in the sense of minimum typical distortion (343 ppm as compared with the optimal overall value of $330 \mathrm{ppm}$ ). Further, after a quick trial-and-error search (changing the maximum and minimum longitudes) it is found that the central meridian scale factor $k_{0}=0.9996$ is indeed the optimal value in the sense of minimum typical distortion for the case where the zones extend not only $3^{\circ}$ to both sides of the central meridian but $3^{\circ} 24^{\prime} 36^{\prime \prime}$. This extension beyond the natural definition limits of the UTM zones is not infrequent, as any surveyor may know, since projects located in UTM zone borders are solved selecting one zone only and computing all points (be they in their natural zone or in the neighboring one) in the same UTM zone. 


\section{Equal-area projections}

\section{Conterminous US}

The Albers Conic Equal-Area projection was used for the National Atlas of the United States until its final edition in 2014, although with a spherical reference surface (Snyder 1987). The US Geological Survey currently uses the version with WGS84 ellipsoid (EPSG5072) for the boundaries known as CONUS onshore (EPSG1323). As it can be seen in Table 8, the standard parallels are already quite well optimized in a compromise between the minimum typical distortion and the minimum extreme distortions.

It could also be studied whether the use of a Lambert Azimuthal Equal-Area projection optimized for the area of interest would produce a map with smaller distortions. As it turns out, this is not the case for the Conterminous US, as the resulting distortion measures (not shown here) do not improve those of the Albers Conic Equal-Area projection (Table 8).

\section{Australia}

In a similar fashion, the Australian Albers EPSG3577 projection can be evaluated and optimized. As it can be seen in Table 9, the projection is already relatively well optimized in the sense of minimum typical distortion. However, if one studies whether the use of a Lambert Azimuthal Equal-Area projection is more convenient for depicting the area of interest (i.e. if it would produce a map with smaller distortions) now the 
answer is positive, as it is shown in Table 10. The proposal is now to use the Lambert Azimuthal Equal-Area projection with origin latitude $\varphi_{0}=27.08^{\circ} \mathrm{S}$ and origin longitude $\lambda_{0}$ $=133.27^{\circ} \mathrm{E}$ for area-preserving representations of Australia onshore (EPSG 2575) territories, since it reduces from 13264 to $5014 \mathrm{ppm}$ (62\% reduction) the typical distortion and from 36801 to $12632 \mathrm{ppm}$ (66\% reduction) the maximum distortion value with respect to the Australian Albers projection.

\section{Conclusions}

Taking advantage of the Fibonacci lattices' optimality for efficiently sampling functions with a geographical distribution, it has been described how general measures for distortion could be computed for the most common conformal and equal-area map projections within the prescribed areas of interest. These computations have been implemented in a tool (TestGrids) open to the use by the journal readers.

Furthermore, the use of a global optimization method, also incorporated in the tool, permits to optimize the map defining parameters in the sense of either minimum typical distortion or minimum extreme distortions (up to the user's choice) and compare results with those obtained using the standard map projection definitions.

Without pretending to exhaust all possible cases of application some examples were provided for map projections, areas of use and corresponding defining parameters that are already relatively well optimized (either in the sense of minimum typical or extreme distortion), in some cases, and others whose defining parameters could be clearly improved or where even the projection used should be changed to significantly minimize the resulting distortions. 
Starting from these examples and using this tool, the reader is given the possibility of further analyses and applications to their cases of interest.

\section{Acknowledgments}

The author is grateful to the editor and the anonymous reviewers for their valuable suggestions, corrections and comments that helped improve the original manuscript.

\section{References}

Agüera-Vega, F., Carvajal-Ramírez, F., Martínez-Carricondo, P. (2017) "Accuracy of Digital Surface Models and Orthophotos Derived from Unmanned Aerial Vehicle Photogrammetry." J. Surv. Eng., 143(2): 04016025.

Airy, G. B. (1861). "Explanation of a projection by balance of errors for maps applying to a very large extent of the Earth's surface, and comparison of this projection with other projections." Edimburgh and Dublin Philosophical Magazine, 4th ser., 22: 409-421.

Annoni, A., Luzet, C., Gubler, E. and Ihde, J. (2003). Map Projections for Europe. European Commission Joint Research Centre, Ispra, Italy. EUR 20120 EN.

Baselga, S. (2007). "Global Optimization Solution of Robust Estimation." J. Surv. Eng., 133(3): 123-128.

Baselga, S. (2011). " Second Order Design of Geodetic Networks by the Simulated Annealing Method" J. Surv. Eng., 137(4): 167-173.

Baselga, S. (2014). Fundamentos de Cartografía Matemática. $2^{\text {nd }}$ Ed. Universitat Politècnica de València, València. 
Baselga, S. (2018). "Fibonacci lattices for the evaluation and optimization of map projections." Comput. Geosci., 117: 1-8.

Canters, F. (2002). Small-scale Map Projection Design. Taylor \& Francis, London.

El-Mowafy, A., and Bilbas, E. (2016). "Quality Control in Using GNSS CORS Network for Monitoring Plate Tectonics: A Western Australia Case Study." J. Surv. Eng., 142(2): 05015003.

ESRI. (2013). Spatial Reference database, projection: 1002004, <http://spatialreference.org/ref/esri/102004/html/> (Jun., 22, 2018)

Fenna, D. (2007). Cartographic Science: A Compendium of Map Projections, with Derivations. CRC Press, Taylor \& Francis Group, Boca Raton, FL.

Gilbert, E. N. (1974). "Distortion in maps." SIAM Rev., 16: 47-62.

González, A. (2010). "Measurement of Areas on a Sphere Using Fibonacci and Latitude-Longitude Lattices." Math. Geosci., 42: 49-64.

INSPIRE D2.8.I.1 (2014). Data Specification on Coordinate Reference Systems Technical Guidelines. European Commission. $<$ http://inspire.ec.europa.eu/documents/Data_Specifications/INSPIRE_DataSpecificatio n_RS_v3.2.pdf> (Jun. 12, 2018).

Jordan, W. (1896). "Der mittlere Verzerrungsfehler." Zeitschrift für Vermessungswesen, 25: $249-252$.

Keinert, B., Innmann, M., Sanger, M., and Stamminger M. (2015). "Spherical Fibonacci Mapping." ACM Trans. Graph., 34(6): 193.

Konečný, J., Qu, Z., and Richtárik P. (2017) "Semi-stochastic coordinate descent." Optim. Method Softw., 32(5): 993-1005. 
Kopp, S., and Kennedy, M. (2000) Understanding Map Projections: GIS by ESRI. ESRI Press, Redlands, CA.

Koshy, T. (2001). Fibonacci and Lucas Numbers with Applications. Wiley-Interscience, New York.

Meyer, T. H. (2010). Introduction to Geometrical and Physical Geodesy: Foundations of Geomatics. ESRI Press, Redlands, CA.

Mozas-Calvache, A. T., and Pérez-García, J. L. (2017) "Analysis and Comparison of Lines Obtained from GNSS and UAV for Large-Scale Maps." J. Surv. Eng., 143(3): 04016028.

Onursal, G., and Kizilsu, Z. (1999) "Simple Approximation of Area Determination on Mercator Chart of Sphere." J. Surv. Eng., 125(4): 203-210.

Pardalos, P. M., and Romeijn, H. E., eds. (2002). Handbook of Global Optimization, Vols. 1\&2, Kluwer Academic, Dordrecht, The Netherlands.

Peters, A. B. (1975). "Wie man unsere Weltkarten der Erde ähnlicher machen kann." Kartographische Nachrichten, 25: 173-183.

Singh, V., Dwivedi, R., Dikshit, O., Singh, A.K. (2016) "First-Order Design of GPS Networks Using Particle Swarm Optimization." J. Surv. Eng., 142(3): 04016002.

Snyder, J. P. (1987). Map Projections: A Working Manual. US Geological Survey, Washington, DC.

Soler, T. and Wang, G. (2016) "Interpreting OPUS-Static Results Accurately." J. Surv. Eng., 142(4): 05016003.

Stem, J. E. (1989) State Plane Coordinate Systems of 1983. NOAA. Manual No. NGS 5. NOAA, 
Silver Spring, MD.

Swinbank, R. and Purser, R. J. (2006). "Fibonacci grids: A novel approach to global modelling." Q. J. Royal Meteorol. Soc., 132: 1769-1793.

United States Department of Energy. (2013). The National Hydropower Map, <https://www.energy.gov/sites/prod/files/2014/03/f9/national_hydropower_map.pdf> (Jun. 22, 2018)

Yetkin, M., and Berber, M. (2013) "Application of the Sign-Constrained Robust LeastSquares

Method to Surveying Networks." J. Surv. Eng., 139(1): 59-65. 
Figure captions

Fig. 1. TestGrids program window. 


\section{Tables}

Table 1. Upper and lower standard parallel latitudes $\left(\varphi_{u}\right.$ and $\left.\varphi_{l}\right)$ with their corresponding typical distortion $\left(\Delta k_{l}\right)$, average, maximum and minimum values of the linear distortion coefficient $\left(k_{\text {lavg }}, k_{\text {lmax }}\right.$ and $\left.k_{\text {lmin }}\right)$, and Gilbert and Peters estimators $\left(E_{G}\right.$ and $\left.E_{P}\right)$ for Lambert Conformal Conic projection for Europe (area of use: $\varphi_{\max }=71^{\circ}, \varphi_{\min }=$ $27^{\circ}, \lambda_{\max }=45^{\circ}, \lambda_{\min }=-30^{\circ}$.

\begin{tabular}{ccccccccc}
\hline Source & $\begin{array}{c}\varphi_{u} \\
\left({ }^{\circ}\right.\end{array}$ & $\begin{array}{c}\varphi_{l} \\
\left({ }^{\circ}\right)\end{array}$ & $\begin{array}{c}\Delta k_{l} \\
(\mathrm{ppm})\end{array}$ & $\begin{array}{c}k_{\text {lavg }} \\
(\mathrm{ppm})\end{array}$ & $\begin{array}{c}k_{\text {Imax }} \\
(\mathrm{ppm})\end{array}$ & $\begin{array}{c}k_{\text {Imin }} \\
(\mathrm{ppm})\end{array}$ & $\begin{array}{c}E_{G} \\
(\mathrm{ppm})\end{array}$ & $\begin{array}{c}E_{P} \\
(\mathrm{ppm})\end{array}$ \\
\hline $\begin{array}{c}\text { INSPIRE D2.8.I.1 (2014) } \\
\begin{array}{c}\text { TestGrids, optimizing for typical } \\
\text { distortion }\end{array}\end{array}$ & 65 & 35 & 24687 & -9147 & 43679 & -34378 & 617 & 11094 \\
$\begin{array}{c}\text { TestGrids, optimizing for extreme } \\
\text { distortions }\end{array}$ & 65.54 & 36.06 & 22434 & -503 & 67567 & -24741 & 496 & 9515 \\
\hline
\end{tabular}

Table 2. Upper and lower standard parallel latitudes $\left(\varphi_{u}\right.$ and $\left.\varphi_{l}\right)$ with their corresponding typical distortion $\left(\Delta k_{l}\right)$, average, maximum and minimum values of the linear distortion coefficient $\left(k_{\text {lavg }}, k_{l \max }\right.$ and $\left.k_{l \min }\right)$, and Gilbert and Peters estimators $\left(E_{G}\right.$ and $\left.E_{P}\right)$ for Geoscience Australia Lambert Conformal Conic projection (area of use: $\varphi_{\max }=$ $\left.9.86^{\circ}, \varphi_{\min }=-43.7^{\circ}, \lambda_{\max }=153.69^{\circ}, \lambda_{\min }=112.85^{\circ}\right)$.

\begin{tabular}{ccccccccc}
\hline Source & $\begin{array}{c}\varphi_{u} \\
\left({ }^{\circ}\right)\end{array}$ & $\begin{array}{c}\varphi_{l} \\
\left({ }^{\circ}\right)\end{array}$ & $\begin{array}{c}\Delta k_{1} \\
(\mathrm{ppm})\end{array}$ & $\begin{array}{c}k_{\text {lavg }} \\
(\mathrm{ppm})\end{array}$ & $\begin{array}{c}k_{\text {lmax }} \\
(\mathrm{ppm})\end{array}$ & $\begin{array}{c}k_{\text {lmin }} \\
(\mathrm{ppm})\end{array}$ & $\begin{array}{c}E_{G} \\
(\mathrm{ppm})\end{array}$ & $\begin{array}{c}E_{P} \\
(\mathrm{ppm})\end{array}$ \\
\hline $\begin{array}{c}\text { EPSG17362 } \\
\begin{array}{c}\text { TestGrids, optimizing for typical } \\
\text { distortion }\end{array}\end{array}$ & -18 & -36 & 13339 & 2219 & 32903 & -12256 & 175 & 5485 \\
$\begin{array}{c}\text { TestGrids, optimizing for extreme } \\
\text { distortions }\end{array}$ & -14.92 & -39.08 & 15151 & -7707 & 22064 & -22065 & 233 & 6806 \\
$\begin{array}{c}\text { Proposed standard parallels } \\
\text { Pand }\end{array}$ & -15 & -39 & 15003 & -7407 & 22402 & -21767 & 228 & 6740 \\
\hline
\end{tabular}

Table 3. Upper and lower standard parallel latitudes $\left(\varphi_{u}\right.$ and $\left.\varphi_{l}\right)$ with their corresponding typical distortion $\left(\Delta k_{l}\right)$, average, maximum and minimum values of the linear distortion coefficient $\left(k_{\text {lavg }}, k_{\text {lmax }}\right.$ and $\left.k_{\text {lmin }}\right)$, and Gilbert and Peters estimators $\left(E_{G}\right.$ and $\left.E_{P}\right)$ for Lambert Conformal Conic projection for Conterminous US (area of use: $\varphi_{\max }=$ $\left.49.38^{\circ}, \varphi_{\min }=24.41^{\circ}, \lambda_{\max }=-66.91^{\circ}, \lambda_{\min }=-124.79^{\circ}\right)$.

\begin{tabular}{ccccccccc}
\hline \multirow{2}{*}{ Source } & $\varphi_{u}$ & $\varphi_{l}$ & $\Delta k_{l}$ & $k_{\text {lavg }}$ & $k_{\text {Imax }}$ & $k_{\text {lmin }}$ & $E_{G}$ & $E_{P}$ \\
& $\left({ }^{\circ}\right)$ & $\left({ }^{\circ}\right)$ & $(\mathrm{ppm})$ & $(\mathrm{ppm})$ & $(\mathrm{ppm})$ & $(\mathrm{ppm})$ & $(\mathrm{ppm})$ & $(\mathrm{ppm})$ \\
\hline
\end{tabular}




\begin{tabular}{ccccccccc}
\hline ESRI 102004 & 45 & 33 & 9132 & 3368 & 25828 & -5460 & 82 & 3380 \\
$\begin{array}{c}\text { TestGrids, optimizing for typical } \\
\text { distortion }\end{array}$ & 44.07 & 29.63 & 7099 & -50 & 17266 & -7909 & 50 & 3046 \\
$\begin{array}{c}\text { TestGrids, optimizing for extreme } \\
\text { distortions }\end{array}$ & 45.95 & 28.19 & 8184 & -4076 & 11950 & -11951 & 67 & 3664 \\
\hline
\end{tabular}

Table 4. Upper and lower standard parallel latitudes $\left(\varphi_{u}\right.$ and $\left.\varphi_{l}\right)$ with their corresponding typical distortion $\left(\Delta k_{l}\right)$, average, maximum and minimum values of the linear distortion coefficient $\left(k_{\text {lavg }}, k_{\text {lmax }}\right.$ and $\left.k_{\text {lmin }}\right)$, and Gilbert and Peters estimators $\left(E_{G}\right.$ and $\left.E_{P}\right)$ for Lambert Conformal Conic projection for Nebraska (area of use: $\varphi_{\max }=43.01^{\circ}, \varphi_{\min }$ $\left.=39.99^{\circ}, \lambda_{\max }=-95.3^{\circ}, \lambda_{\min }=-104.06^{\circ}\right)$.

\begin{tabular}{|c|c|c|c|c|c|c|c|c|}
\hline Source & $\begin{array}{l}\varphi_{u} \\
\left(^{\circ}\right)\end{array}$ & $\begin{array}{l}\varphi_{l} \\
\left({ }^{\circ}\right)\end{array}$ & $\begin{array}{c}\Delta k_{1} \\
(\mathrm{ppm})\end{array}$ & $\begin{array}{c}k_{\text {lavg }} \\
(\mathrm{ppm})\end{array}$ & $\begin{array}{c}k_{\operatorname{lmax}} \\
(\mathrm{ppm})\end{array}$ & $\begin{array}{c}k_{1 \min } \\
(\mathrm{ppm})\end{array}$ & $\begin{array}{c}E_{G} \\
(\mathrm{ppm})\end{array}$ & $\begin{array}{c}E_{P} \\
(\mathrm{ppm})\end{array}$ \\
\hline EPSG2819 & 43 & 40 & 248 & -226 & 4 & -341 & 0 & 113 \\
\hline $\begin{array}{l}\text { TestGrids, optimizing for typical } \\
\text { distortion }\end{array}$ & 42.37 & 40.63 & 103 & 0 & 233 & -115 & 0 & 44 \\
\hline $\begin{array}{c}\text { TestGrids, optimizing for extreme } \\
\text { distortions }\end{array}$ & 42.57 & 40.44 & 118 & -57 & 173 & -173 & 0 & 53 \\
\hline
\end{tabular}

Table 5. Scale factor of the central meridian $\left(k_{0}\right)$ and central meridian longitude $\left(\lambda_{0}\right)$ along with the corresponding typical distortion $\left(\Delta k_{l}\right)$, average, maximum and minimum values of the linear distortion coefficient $\left(k_{\text {lavg }}, k_{\text {lmax }}\right.$ and $k_{\text {Imin }}$ ), and Gilbert and Peters estimators $\left(E_{G}\right.$ and $E_{P}$ ) for Transverse Mercator projection for Florida East (area of use: $\left.\varphi_{\max }=30.83^{\circ}, \varphi_{\min }=24.41^{\circ}, \lambda_{\max }=-79.97^{\circ}, \lambda_{\min }=-82.33^{\circ}\right)$.

\begin{tabular}{|c|c|c|c|c|c|c|c|c|}
\hline Source & $\begin{array}{c}k_{0} \\
(\mathrm{ppm})\end{array}$ & $\begin{array}{l}\lambda_{0} \\
\left({ }^{\circ}\right)\end{array}$ & $\begin{array}{c}\Delta k_{1} \\
(\mathrm{ppm})\end{array}$ & $\begin{array}{c}k_{\text {lavg }} \\
(\mathrm{ppm})\end{array}$ & $\begin{array}{r}k_{\operatorname{lmax}} \\
(\mathrm{ppm}) \\
\end{array}$ & $\begin{array}{c}k_{\operatorname{lmin}} \\
(\mathrm{ppm})\end{array}$ & $\begin{array}{c}E_{G} \\
(\mathrm{ppm})\end{array}$ & $\begin{array}{c}E_{P} \\
(\mathrm{ppm})\end{array}$ \\
\hline EPSG2777 & 0.999941177 & -81 & 56 & 0 & 165 & -59 & 0 & 23 \\
\hline $\begin{array}{l}\text { TestGrids, optimizing for typical } \\
\text { distortion }\end{array}$ & 0.99994421 & -81.15 & 50 & 0 & 121 & -56 & 0 & 21 \\
\hline $\begin{array}{l}\text { TestGrids, optimizing for } \\
\text { extreme distortions }\end{array}$ & 0.99991186 & -81.15 & 60 & -32 & 88 & -88 & 0 & 26 \\
\hline $\begin{array}{l}\text { Proposed solution with the same } \\
\text { scale factor for Florida East and } \\
\text { Florida West }\end{array}$ & 0.999918 & -81.15 & 56 & -26 & 94 & 82 & 0 & 25 \\
\hline
\end{tabular}


Table 6. Scale factor of the central meridian $\left(k_{0}\right)$ and central meridian longitude $\left(\lambda_{0}\right)$ along with the corresponding typical distortion $\left(\Delta k_{l}\right)$, average, maximum and minimum values of the linear distortion coefficient $\left(k_{\text {lavg }}, k_{\text {lmax }}\right.$ and $k_{\text {Imin }}$ ), and Gilbert and Peters estimators $\left(E_{G}\right.$ and $\left.E_{P}\right)$ for Transverse Mercator projection for Florida West (area of use: $\left.\varphi_{\max }=29.6^{\circ}, \varphi_{\min }=26.27^{\circ}, \lambda_{\max }=-81.13^{\circ}, \lambda_{\min }=-83.34^{\circ}\right)$.

\begin{tabular}{|c|c|c|c|c|c|c|c|c|}
\hline Source & $\begin{array}{c}k_{0} \\
(\mathrm{ppm})\end{array}$ & $\begin{array}{l}\lambda_{0} \\
\left({ }^{\circ}\right)\end{array}$ & $\begin{array}{c}\Delta k_{1} \\
(\mathrm{ppm})\end{array}$ & $\begin{array}{c}k_{\text {lavg }} \\
(\mathrm{ppm})\end{array}$ & $\begin{array}{r}k_{\operatorname{lmax}} \\
(\mathrm{ppm})\end{array}$ & $\begin{array}{c}k_{l \min } \\
(\mathrm{ppm})\end{array}$ & $\begin{array}{c}E_{G} \\
(\mathrm{ppm})\end{array}$ & $\begin{array}{c}E_{P} \\
(\mathrm{ppm})\end{array}$ \\
\hline EPSG2778 & 0.999941177 & -82 & 56 & -2 & 161 & -59 & 0 & 23 \\
\hline $\begin{array}{l}\text { TestGrids, optimizing for typical } \\
\text { distortion }\end{array}$ & 0.99995128 & -82.24 & 44 & 0 & 101 & -49 & 0 & 19 \\
\hline $\begin{array}{l}\text { TestGrids, optimizing for } \\
\text { extreme distortions }\end{array}$ & 0.99992517 & -82.24 & 51 & -26 & 75 & -75 & 0 & 23 \\
\hline $\begin{array}{c}\text { Proposed solution with the same } \\
\text { scale factor for Florida East and } \\
\text { Florida West }\end{array}$ & 0.999918 & -82.24 & 55 & -33 & 69 & -82 & 0 & 24 \\
\hline
\end{tabular}

Table 7. Scale factor of the central meridian $\left(k_{0}\right)$ and central meridian longitude $\left(\lambda_{0}\right)$ along with the corresponding typical distortion $\left(\Delta k_{l}\right)$, average, maximum and minimum values of the linear distortion coefficient $\left(k_{\text {lavg }}, k_{\text {lmax }}\right.$ and $k_{1 m i n}$ ), and Gilbert and Peters estimators $\left(E_{G}\right.$ and $\left.E_{P}\right)$ for Universal Transverse Mercator projection, zone 31 (area of use: $\left.\varphi_{\max }=84^{\circ}, \varphi_{\min }=-80^{\circ}, \lambda_{\max }=6^{\circ}, \lambda_{\min }=0^{\circ}\right)$.

\begin{tabular}{ccccccccc}
\hline Source & $\begin{array}{c}k_{0} \\
(\mathrm{ppm})\end{array}$ & $\begin{array}{c}\lambda_{0} \\
\left({ }^{\circ}\right)\end{array}$ & $\begin{array}{c}\Delta k_{I} \\
(\mathrm{ppm})\end{array}$ & $\begin{array}{c}k_{\text {lavg }} \\
(\mathrm{ppm})\end{array}$ & $\begin{array}{c}k_{\text {Imax }} \\
(\mathrm{ppm})\end{array}$ & $\begin{array}{c}k_{\min } \\
(\mathrm{ppm})\end{array}$ & $\begin{array}{c}E_{G} \\
(\mathrm{ppm})\end{array}$ & $\begin{array}{c}E_{P} \\
(\mathrm{ppm})\end{array}$ \\
\hline $\begin{array}{c}\text { UTM zone } 31 \\
\text { TestGrids, optimizing for typical } \\
\text { distortion }\end{array}$ & 0.999600 & 3 & 343 & -91 & 976 & -400 & 0 & 149 \\
$\begin{array}{c}\text { TestGrids, optimizing for extreme } \\
\text { distortions }\end{array}$ & 0.999690 & 3 & 330 & 0 & 1067 & -310 & 0 & 134 \\
\hline
\end{tabular}

Table 8. Upper and lower standard parallel latitudes $\left(\varphi_{u}\right.$ and $\left.\varphi_{l}\right)$ with their corresponding typical distortion $\left(\Delta k_{l}\right)$, average, maximum and minimum values of the linear distortion coefficient $\left(k_{\text {lavg }}, k_{\text {lmax }}\right.$ and $\left.k_{\text {lmin }}\right)$, and Gilbert and Peters estimators $\left(E_{G}\right.$ and $E_{P}$ ) for Albers Conic Equal-Area projection for Conterminous US (area of use: $\varphi_{\max }=$ $\left.49.38^{\circ}, \varphi_{\min }=24.41^{\circ}, \lambda_{\max }=-66.91^{\circ}, \lambda_{\min }=-124.79^{\circ}\right)$. 


\begin{tabular}{|c|c|c|c|c|c|c|c|c|}
\hline Source & $\begin{array}{l}\varphi_{u} \\
\left({ }^{\circ}\right)\end{array}$ & $\begin{array}{l}\varphi_{l} \\
\left({ }^{\circ}\right)\end{array}$ & $\begin{array}{c}\Delta k_{1} \\
(\mathrm{ppm})\end{array}$ & $\begin{array}{c}k_{\text {lavg }} \\
(\mathrm{ppm})\end{array}$ & $\begin{array}{r}k_{\operatorname{lmax}} \\
(\mathrm{ppm})\end{array}$ & $\begin{array}{c}k_{l \min } \\
(\mathrm{ppm})\end{array}$ & $\begin{array}{c}E_{G} \\
(\mathrm{ppm})\end{array}$ & $\begin{array}{c}E_{P} \\
(\mathrm{ppm})\end{array}$ \\
\hline EPSG5072 & 45.5 & 29.5 & 7328 & 27 & 14245 & -14045 & 54 & 3252 \\
\hline $\begin{array}{l}\text { TestGrids, optimizing for typical } \\
\text { distortion }\end{array}$ & 44.52 & 30.1 & 7083 & 25 & 17359 & -17062 & 50 & 3044 \\
\hline $\begin{array}{l}\text { TestGrids, optimizing for extreme } \\
\text { distortions }\end{array}$ & 46.28 & 28.54 & 8172 & 33 & 12058 & -11914 & 67 & 3644 \\
\hline
\end{tabular}

Table 9. Upper and lower standard parallel latitudes $\left(\varphi_{u}\right.$ and $\left.\varphi_{l}\right)$ with their corresponding typical distortion $\left(\Delta k_{l}\right)$, average, maximum and minimum values of the linear distortion coefficient $\left(k_{\text {lavg }}, k_{\text {lmax }}\right.$ and $\left.k_{\text {lmin }}\right)$, and Gilbert and Peters estimators $\left(E_{G}\right.$ and $\left.E_{P}\right)$ for Australia Albers Conic Equal-Area projection (area of use: $\varphi_{\max }=-9.86^{\circ}, \varphi_{\min }=$ $\left.43.7^{\circ}, \lambda_{\max }=153.69^{\circ}, \lambda_{\min }=112.85^{\circ}\right)$.

\begin{tabular}{|c|c|c|c|c|c|c|c|c|}
\hline Source & $\begin{array}{l}\varphi_{u} \\
\left({ }^{\circ}\right)\end{array}$ & $\begin{array}{l}\varphi_{l} \\
\left({ }^{\circ}\right)\end{array}$ & $\begin{array}{c}\Delta k_{1} \\
(\mathrm{ppm})\end{array}$ & $\begin{array}{c}k_{\text {lavg }} \\
(\mathrm{ppm})\end{array}$ & $\begin{array}{c}k_{l \max } \\
(\mathrm{ppm})\end{array}$ & $\begin{array}{c}k_{\operatorname{lmin}} \\
(\mathrm{ppm})\end{array}$ & $\begin{array}{c}E_{G} \\
(\mathrm{ppm})\end{array}$ & $\begin{array}{c}E_{P} \\
(\mathrm{ppm})\end{array}$ \\
\hline EPSG3577 & -18 & -36 & 13264 & 88 & 36801 & -35495 & 176 & 5472 \\
\hline $\begin{array}{l}\text { TestGrids, optimizing for typical } \\
\text { distortion }\end{array}$ & -17.55 & -37.06 & 13049 & 85 & 32212 & -31207 & 170 & 5601 \\
\hline $\begin{array}{c}\text { TestGrids, optimizing for extreme } \\
\text { distortions }\end{array}$ & -15.35 & -39.5 & 15184 & 115 & 22501 & -22006 & 231 & 6773 \\
\hline
\end{tabular}

Table 10. Origin latitude and longitude $\left(\varphi_{0}\right.$ and $\left.\lambda_{0}\right)$ with their corresponding typical distortion $\left(\Delta k_{1}\right)$, average, maximum and minimum values of the linear distortion coefficient $\left(k_{\text {lavg }}, k_{\text {lmax }}\right.$ and $\left.k_{\text {lmin }}\right)$, and Gilbert and Peters estimators $\left(E_{G}\right.$ and $\left.E_{P}\right)$ for Australia Lambert Azimuthal Equal-Area projection (area of use: $\varphi_{\max }=-9.86^{\circ}, \varphi_{\min }=$ $\left.43.7^{\circ}, \lambda_{\max }=153.69^{\circ}, \lambda_{\min }=112.85^{\circ}\right)$.

\begin{tabular}{ccccccccc}
\hline Source & $\begin{array}{c}\varphi_{0} \\
\left({ }^{\circ}\right)\end{array}$ & $\begin{array}{c}\lambda_{0} \\
\left({ }^{\circ}\right)\end{array}$ & $\begin{array}{c}\Delta k_{l} \\
(\mathrm{ppm})\end{array}$ & $\begin{array}{c}k_{\text {lavg }} \\
(\mathrm{ppm})\end{array}$ & $\begin{array}{c}k_{\text {Imax }} \\
(\mathrm{ppm})\end{array}$ & $\begin{array}{c}k_{\text {Imin }} \\
(\mathrm{ppm})\end{array}$ & $\begin{array}{c}E_{G} \\
(\mathrm{ppm})\end{array}$ & $\begin{array}{c}E_{P} \\
(\mathrm{ppm})\end{array}$ \\
\hline $\begin{array}{c}\text { TestGrids, optimizing for typical } \\
\text { distortion }\end{array}$ & -27.08 & 133.27 & 5014 & 13 & 12632 & -12475 & 25 & 1978 \\
$\begin{array}{c}\text { TestGrids, optimizing for extreme } \\
\text { distortions }\end{array}$ & -27.94 & 133.27 & 5054 & 13 & 12426 & -12273 & 26 & 1994 \\
\hline
\end{tabular}

